\title{
So Much More Than Selfies: Twitter for Publication and \#OwnVoices Narratives
}

\author{
Victoria Shropshire and Sarah Tytler
}

\begin{abstract}
This paper discusses the advantages of using Twitter in the classroom as a digital creative writing medium and platform for publication of research and writing. We advocate for the inclusion of digital and social media in the classroom, allowing for a multimodal learning environment that increases student participation, boosts creativity, and encourages student engagement with material across disciplines. Finally, our research provides examples of best practices for educators and program directors looking to integrate Twitter into their curriculum.
\end{abstract}

Index Terms-Creative writing, digital tools, multimodal learning, student engagement, self-publication, Twitter.

\section{INTRODUCTION}

The role social media should play in education remains unclear; some teachers, schools, and districts actively try to keep students away from social networking sites during the school day, while others see almost infinite potential in the use of new media in schools, and a large number of stake-holders remain uncertainly positioned somewhere between these two extremes [1]. Twitter as a social media platform is often dismissed as a purely egotistical or autobiographical application, but it has the potential for much more--particularly when integrated effectively in academic environments [2]-[4]. The vast majority of Twitter users tweet content related to their personal lives--or their reactions and opinions to others' content [5]. As Janelle Adsit reflects in her essay on creative nonfiction and social media, "one cannot fully catalogue the manifold reasons a writer might have for composing a tweet or personal essay, but among them is the compulsion to both record and to tell" [6]. And yet the social media platform's greatest strength is its interconnectivity; indeed, users who infrequently interact with other users, and users who post only about themselves, have on average fewer followers than those who don't [7].

Finding new ways to incorporate or redirect its autobiographical function is a crucial aspect of successfully including Twitter into any curriculum. Twitter incorporates multimodality and creative writing into all discipline and subject areas, which promotes the synthesis and application of knowledge beyond the classroom, but must be included as part of a deliberate and practical pedagogy. Two studies suggest Twitter use encourages concise writing--a benefit to any classroom [8], [9]--and Chen \& Chen (2012) found Twitter helped make students more willing to consult their

Manuscript received December 20, 2017; revised August 30, 2018.

The authors are with the School of Critical Studies: Creative Writing, University of Glasgow, Glasgow, Scotland, UK (email: v.shropshire.1@ research.gla.ac.uk, s.tytler.1@ research.gla.ac.uk). instructors when they were uncertain of their understanding [10]. In a large lecture-class setting, Elavsky and colleagues (2011) found that, when given the opportunity, the majority of students voluntarily contributed questions and comments to a live Twitter feed during class sessions [11]. This "back channel" activity included both student-instructor and student-student communication, and was found to deepen and extend the class's potential for engagement with course themes. Our research advocates for the inclusion of Twitter in the classroom as a self-publication tool for students looking to add their voices to a wider disciplinary, even global, conversation.

\section{PRACTICE-BASED RESEARCH}

\section{A. Observations from the Classroom}

As a writing instructor at an American university, Prof. Shropshire found Twitter, specifically, to be an innovative and effective springboard to the learning outcomes (research skills and improved writing) for her English composition and rhetoric courses. During a three-year study (from 2011-2014), Prof. Shropshire also found that Twitter: aided in improving student motivation and engagement; helped students strengthen relationships; developed a more collaborative view of learning; added new dimensions to student research and rhetorical analysis; and helped students make inspiring connections between the world and their writing and research processes.

In both Prof. Shropshire and Ms. Tytler's experiences, using Twitter has especially benefitted students who belong to marginalized communities or are very shy in face-to-face classroom learning environments. "Twitfic," as it's commonly known, or micro-fiction, is a growing market for writers who embrace the digital age and the extreme self-restriction of telling a story in a single tweet. For marginalized students who not only struggle with class participation, but would also find it difficult to navigate the institutional barriers in traditional publishing, Twitter offers a free, open path to making their voices heard [12]. By providing a structured and supportive environment for students to apply their learning in a creative endeavor, educators build a classroom of practice-based research where students can demonstrate that they have synthesized the information and can apply it to new and far-reaching situations.

\section{B. Data-Driven Decisions}

Twitter's asynchronous nature enables those in a feed to interact over time and space, expanding the classroom and its ideas [13], which is particularly beneficial to students who 
suffer from learning difficulties, social anxieties, or trauma due to loss [14]. As Graeme Harper puts it in "Creative Writing in the Age of Synapses," "nonlinearity means an opportunity to combine more or interconnect greater, and to do so successfully" [15]. The ultimate goal of incorporating Twitter is a student-centered environment where educators play the role of facilitators: facilitating the interactions and dialogues of students with each other, themselves, the material, and the greater societal context in which they're learning. This interconnectedness naturally lends itself to critical analysis, as students weigh the intersectional and complicated relationships of varying interests and voices--including their own. Michael Dean Clark calls this mix of critical conversation "the useful inefficiency of the creative process" [16].

Beyond the classroom, employers have added social media literacy to their list of desired skills, which includes technological proficiency as well as the ability to critically read, investigate, and respond to digital content [17]. In fact, innovation or creativity ranks above such other employee skills as client management skills, sales or marketing skills, and even resilience as the most important skills HR decision-makers believe should be developed in employees over the next five years [18].

\section{Twitter for Research, Twitter for Creativity}

Students, through application, understand that the need to communicate effectively with social media is not just for sharing news of your vacation meals or video of your puppy's romp through the snow. Beyond specialized disciplinary work, there is the need for students to learn to access, analyze, and synthesize information in productive and inventive ways; the digital (including social) media and technology is here to stay, and the new (glocalized) marketplace will demand their proficiency in it [19]. Not only do they need to accept the wide variety of potential audiences and types of writings in our modern world, but to become aware of how these communications are delivered and their impact on composition.

In Prof. Shropshire's own classroom, Twitter boosted students' confidence by giving value to their voices. Rather than feeling like a "spectator" of the research, they felt a keen increase of ownership over the process, in addition to the composition that they later created using their own, original research. It's not about finding the "right" answer or agreeing with a scholar--or even the professor--but mutual engagement and listening that's required for true learning [20]. Collaborative elements were linked to others, such as time management and accountability; students prone to procrastination felt the pressure to get their research started and contribute to the community conversations and document. Twitter added more feedback on the process of both research and writing, and it helped students form and maintain small writing groups and use peer review.

Using these tools helped students achieve a deeper understanding of their topics and locate and analyze more diverse sources, all of which contributed to better products (annotated bibliographies, papers, and oral presentations). This classroom socio-cultural practice of scholarship through social interaction and the development of shared practices allows students to use Twitter as "an emerging and evolving network of scholar-learners where scholarly practices may be created, refined, performed, shared, discussed, and negotiated" [21].

\section{The \#OwnVoices Movement}

\section{A. Social Justice in Cyberspace}

The \#OwnVoices hashtag on Twitter, much like similar tags \#WeNeedDiverseBooks, \#diversebooks, and \#diversityinfiction, were the direct result of a refusal on the part of mainstream publishing venues to create more inclusive environments both in-text and out. Members of marginalized groups have been demanding--loudly--for years for greater representation of themselves in the pages of novels, short stories, and poems, as well as pushing for a more diverse staff within publishing and a more diverse set of published authors themselves. N. K. Jemisin, for example, in an interview with Fireside Fiction in the wake of a study which found zero Black authors had been published in any of the major speculative fiction magazines, expressed a distinct lack of surprise at the result [22]. She explained to interviewer Brian White that Black writers and authors of speculative fiction, after years of being shut out of traditional publishing venues, have turned to self-publication online, and self-promotion within the online community, as a route to making their fiction visible--a path similar to that taken by other marginalized communities [23]. In a similar vein, William Wong remarks that, when it comes to representation of Asian Americans in American media, characterizations largely fall into one of two categories: "a 'model minority' who excels in academics and business or bad guys like gangsters, influence-peddling political contributors, and spies for China" [24]. Sadly, this leaves little space for the greater portion of complex, well-rounded, realistic portrayals which could exist if given the chance. Wong goes on to note that this "absence of in-depth coverage of Asian Americans" leads to a majority-White audience believing that the stereotypical portrayals of "all study, no play" or "mafia gangster" are accurate generalizations of what it means to be Asian American in America [25].

Fireside has not been the only report on the disproportional publishing statistics in the English-speaking world. Both the annual VIDA count and a Spread the Word's report funded in part by Arts Council England found that the publishing industry itself, the authors, and the protagonists of the English-speaking world are predominantly White, male, and straight. [26], [27]. However, in the speculative fiction world specifically, fiction by Chinese and Chinese-American authors (either written originally in English or translated into English) is currently having a "moment." The commercial success of authors such as Cixin Liu's Remembrance of Earth's Past (usually called The Three-Body Problem after the first book's title), has demonstrated to a majority White, Western European publishing world that East Asian science fiction and fantasy fiction is not only in high demand, but highly profitable [28]-[31]. It is unfortunate that what is so obvious to so many was so surprising to so few, but it proves that the audience is already there, and already eager for more: 
writers just need to be given the opportunity to get their work out into the world.

\#OwnVoices is a natural reaction to the desire by readers to see themselves represented in the stories they read, and to see themselves represented in realistic, complex, nuanced ways. The hashtag is meant to highlight stories by writers about protagonists who are members of the same marginalized group(s) as author themselves. Twitter, as a free-to-use, open platform, allows anyone to become a published author. It is important to note here that there are two kinds of visibility and inclusion: increased numbers of writers, editors, publishers, and marketers from marginalized groups, and increased number of characters from marginalized groups--and \#OwnVoices satisfies both.

\section{B. Pitfalls of Self-publication}

Unfortunately, the high levels of satisfaction that authors report after the self-publishing process are not matched by high levels of income [32], [33]. Across demographics, self-published authors report positive feelings about the process, and they typically go on to self-publish again, but as The Guardian reported back in 2012, fewer than half of all authors earn more than 500USD [34]. Due to the emotional and psychological satisfaction, if not the financial satisfaction, most authors achieve from publishing their ideas the benefits of self-publishing in the classroom as a way for students to gain both experience and exposure still outweigh the unlikely prospect of any great financial gain. However, one outsize danger to authors' satisfaction, especially on a social media platform such as Twitter, is that of trolling and abuse.

The term "troll," for those users on the internet who deliberately hijack debates, forums, or commenting threads, is common enough that almost all users have encountered the behavior, or at least witnessed it. Online abuse, in the form of emotional violence, threats of physical violence, "doxxing" (revealing someone's private or personal data online), and "swatting" (placing a fraudulent emergency call requiring police response to the victim's home) is common, and long been one of the major complaints by users about Twitter and its company's lack of adequate response [35]. One of the largest barriers for educators to the inclusion of Twitter and students' self-published works is preparation for a response to this threat. The most effective means of combatting trolling behaviour and online abuse is to keep all the classroom accounts private. This measure does, however, mean that content is not "published" in a broader sense of the term. Educators must have in place ahead of time an action plan for dealing with trolls (both in the classroom and out) and a strict set of guidelines and procedures for themselves and their students to follow. Educators should ensure that their students are aware of and know how to use tools such as blocking and reporting on Twitter, and they should make themselves available and be prepared to coach students who might have their own marginalized status used against them by an anonymous Twitter user halfway around the world.

\section{A Community of One's Own}

World-public visibility also means people who are part of tiny minorities can still find fiction about people like them; they can publish things about themselves and find other people like themselves; and they can find a camaraderie grounded in first-hand experience which may not be possible for them in person. People who find it difficult to leave the home, either due to age or physical or mental disability, can form meaningful connections with others which would not have been possible in an earlier age. This social community reduces feelings of isolation and allows those users to participate in the broader conversation of tweets.

"A tweet stream is a constantly evolving, co-constructed conversation. Establishing a presence and inserting oneself into a conversation requires understanding conventions that have arisen in the community and deciding when and how to use them to support one's purposes" [36]. Using Twitter is not merely a matter of social media use to "meet students where they live," it's using a social space as an engaging learning tool to demonstrate and explore practical applications to the skills students are developing in their writing and research processes.

Although Astin uses the word "involvement," we find his definition: "the amount of physical and psychological energy that the student devotes to the academic experience" to be equally relevant as a definition for the term "engagement" [37], which today is empirically linked to student learning outcomes. Kuh (2009) breaks down the assessment of engagement into two specific areas: in-class engagement and out-of-class engagement [38]. This small first foray into the academic uses of Twitter for Prof. Shropshire's first-year students accomplished both. Students used the tool in-class to engage with the ideas of all participants, then proceeded to build on these, engaging in discourse well beyond the class meeting, and using it to inform their work on writing assignments. Extended conversations regarding rhetorical choices and audience included links and references that students added to the conversation through tweets; students held responsible conversations about offensive words and ideas, stereotyping, and racial and ethnic material used as humor in modern satire, which were previously difficult topics to for first-years to discuss.

Twitter provided a unique and comfortable venue, where the voices of students were asserted and--more importantly--heard. Reading and commenting on the Twitter feed allowed students who were introverted the opportunity to comfortably insert their ideas into the discussion via the back-channel but encouraged them to bring these to traditional class discussions as well. Students would often read the post, then turn (physically) to the author and ask for elaboration, encouraging thoughtful responses in most cases, and in some cases, collaborative research to support and explain an idea further. Students of diverse racial, ethnic, and religious backgrounds asserted concise and thoughtful contributions to uncomfortable or sensitive topics: referencing the tweet stream and pulling from multiple external examples linked there allowed students, who were otherwise uneasy about how to enter a discourse about controversial topics, a bridge to do so.

\section{CONCLUSION}

The ubiquitous nature of smart phones, tablets, laptops, 
and other "Internet of Things" devices is little more than a potential classroom distraction to many, and the risks of integrating them deliberately are legitimate, but used well and deliberately applied in the curriculum towards specific learning objectives, social media has the potential to increase both engagement and involvement, satisfaction, production (and grades) in addition to being a good way to engage students in experiential learning [39], [40].

The Twitter uses detailed in this article show that the use of Twitter increased productivity, built student participation and confidence, added dimensions to student research, writing, and rhetorical analysis skills, and improved both overall engagement and collaborative learning. The primary benefits of incorporating Twitter in the classroom include: encouraging participation and discussion well beyond the classroom; increasing student engagement with course materials and each other for collaborative learning processes; supporting diverse learning styles with multiple avenues of information access; and building student confidence as researchers, writers, and critical readers. Although educators cannot simply walk into a classroom (digital or otherwise) without a concrete plan for incorporating Twitter, it is not so difficult to add to a curriculum as to be impossible. Having a plan in place for how discussions will progress on the platform, and which, and what actions educators and students will take in the event of online abuse, will greatly enhance the success of the endeavor, and build confidence for educators unsure of the platform or its applicability to their material. As with most other media and most other classroom planning, a specific and deliberate set of expectations and learning objectives creates a clear way for teachers and students both to ensure that they meet their educational goals.

\section{REFERENCES}

[1] J. A. Bowen and J. Bass, Teaching Naked: How Moving Technology Out of Your College Classroom Will Improve Student Learning, San Francisco, CA: John Wiley \& Sons, 2012, ch. 6.

[2] D. Bruff, "A social network can be a learning network," The Chronicle for Higher Education, November, 2011.

[3] M. Berry, "Looking over mobile media, creative practice and ethnography," Creating with Mobile Media, September 30, 2017, pp. 153-166.

[4] A. Maragiannis and J. Jefferies, "'Twitter': Practice in writing: A recipe for creativity \& creative interpretation," in Proc. the 21st Symposium on Electronic Arts, International Symposium on Electronic Art, May 19, 2016.

[5] Y. Liu, C. Kliman-Silver, and A. Mislove, "The tweets they are a-Changin': Evolution of Twitter users and behavior," International AAAI Conference on Weblogs and Social Media, vol. 13, 2014.

[6] J. Adsit, "Giving an account of oneself: teaching identity construction and authorship in creative nonfiction and social media," Creative Writing in the Digital Age: Theory, Practice, and Pedagogy, New York: Bloomsbury, 2015, p. 106.

[7] D. Thomas and J. S. Brown, A New Culture of Learning: Cultivating the Imagination for a World of Constant Change, 2011.

[8] T. B. Crews and W. L. Stitt-Gohdes, "Incorporating facebook and twitter in a service-learning project in a business communication course," Business Communication Quarterly, vol. 75, no. 1, pp. 76-79, March, 2012.

[9] P. R. Lowenthal, and J. C. Dunlap, "From pixel on a screen to real person in your students' lives: Establishing social presence using digital storytelling," The Internet and Higher Education, vol. 13, no. 1, pp. 70-72, January, 2010

[10] L. Chen and T. L. Chen, "Use of Twitter for formative evaluation: reflections on trainer and trainees' experiences," British Journal of Educational Technology, vol. 43, no. 2, pp. E49-E52, February, 2012.
[11] C. M. Elavsky, C. Mislan, and S. Elavsky, "When talking less is more exploring outcomes of Twitter usage in the large-lecture hall," Learning, Media and Technology, vol. 3, no. 3, pp. 215-233, April, 2011.

[12] S. Tytler, "'Twitfic', twine, and student-centred learning: combining creativity and coding in the classroom," Africa International Journal of Management, Education and Governance, vol. 2, no. 3, pp. 21-34, October, 2017

[13] E. Kassen-Noor, "Twitter as a teaching practice to enhance active and informal learning in higher education: The case for sustainable tweets," Active Learning in Higher Education, vol. 13, no. 1, pp. 9-21, February, 2012.

[14] A. Barak and R. Leichtentritt, "Creative writing after traumatic loss: Towards a generative writing approach," The British Journal of Social Work, vol. 47, Issue 3, 1 April 2017, pp. 936-954.

[15] G. Harper, "Creative writing in the age of synapses," Creative Writing in the Digital Age: Theory, Practice, and Pedagogy, New York: Bloomsbury, 2015, p. 9.

[16] M. D. Clark, "The marketable creative: Using technology and broader notions of skill in the fiction course," Creative Writing in the Digital Age: Theory, Practice, and Pedagogy, New York: Bloomsbury, 2015, p. 67.

[17] Q. Erik, Socialnomics: How Social Media Transforms the Way We Live and Do Business, Hoboken, NJ: John Wylie \& Sons, 2009, ch. 7.

[18] (January, 2014). The Flux Report: Building a Resilient Workforce in the Face of Flux. Right Management, Manpower Group, London, UK [Online]. Available: http://www.rightmanagement.co.uk/wps/wcm/connect/350a18c6-6b19 -470d-adba-88c9e0394d0b/Right+Management+Flux+Report+Spread .pdf?MOD=AJPERES

[19] J. Hird, "11 ways to measure the value of social media," Series on Internet Marketing Strategies Briefings Econsultancy: Digital Marketers United, August 1, 2011.

[20] S. A. Ambrose, M. W. Bridges, M. DiPietro, M. C. Lovett, and M. K Norman, How Learning Works: Seven Research-Based Principles for Smart Teaching, San Francisco, CA: Jossey-Bass, 2010.

[21] G. Veletsianos, "Higher education scholars' participation and practices on Twitter," Journal of Computer Assisted Learning, vol. 28, p. 337, August 2012.

[22] N. K. Jemisin, "Interview with N.K. Jemisin: \#blackspecfic: A fireside fiction company special report," Fireside Fiction, July, 2016.

[23] D. Gunn, "Asexual authors speak out about representation (and ostracization) in fiction," The Establishment, January 10, 2018.

[24] W. Wong, Yellow Journalist: Dispatches from America, Philadelphia, PA: Temple University Press, 2001, ch. 7, p. 127.

[25] W. Wong, Yellow Journalist: Dispatches from America, Philadelphia, PA: Temple University Press, 2001, ch. 12, p. 209.

[26] (March 30, 2016). The 2015 VIDA Count. VIDA: Women in Literary Arts, New York, NY. [Online]. Available: http://www.vidaweb.org/the-2015-vida-count

[27] (2015). Writing the Future: Black and Asian Writers and Publishers in the UK Market Place. Spread the Word. [Online]. Available: https://www.spreadtheword.org.uk/writing-the-future

[28] C. Liu, The Three-Body Problem, London, UK: Head of Zeus, 2015.

[29] K. Liu, The Grace of Kings, London, UK: Head of Zeus, 2015.

[30] M. Lu, Legend, London, UK: Penguin, 2012.

[31] R. Manthorpe, "Cixin Liu is the author of your next favourite Sci-Fi novel," Wired, October 29, 2016.

[32] A. Baverstock and J. Steinitz, "What satisfactions do self-publishing authors gain from the process?" Learned Publishing, vol. 26, no. 4, pp. 272-282, October 2013.

[33] A. Steiner. (November 2017). The global book: micropublishing, conglomerate production, and digital market structures. Publishing Research Quarterly. [Online]. Available: https://doi.org/10.1007/s12109-017-9558-8.

[34] A. Flood, "Stop the Press: Half of Self-Published Authors Earn Less Than \$500," The Guardian, May 24, 2012.

[35] D. Alba, "Silicon valley finally gets real about troll control," Wired, 8 February, 2017.

[36] C. Greenhow, and B. Gleason, "Twitteracy: Tweeting as a new literacy practice," The Educational Forum, vol. 76, no. 4, pp. 471, October 2012.

[37] A. Astin, "Student involvement: A developmental theory for higher education," Journal of College Student Personnel, vol. 25, p. 297, July, 1984.

[38] G. D. Kuh, "What student affairs professionals need to know about student engagement," Journal of College Student Development, vol. 50, no. 6, pp. 683-706, November, 2009. 
[39] R. Junco, G. Heiberger, and E. Loken, "The effect of Twitter on college student engagement and grades," Journal of Computer Assisted Learning, vol. 27, no. 2, pp. 119-132, November, 2010.

[40] S. B. Rinaldo, S. Tapp, and D. A. Laverie, "Learning by tweeting: Using twitter as a pedagogical tool," Journal of Marketing Education, vol. 33, no. 2, pp. 1-10, May, 2011.

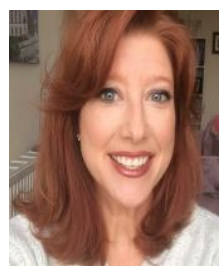

Victoria Shropshire was born in the U.S. in 1973, and earned the bachelor of arts degrees in English and literature from the University of Kansas in 1996 and a masters of professional writing from the University of Southern California in 1999.

She has 18 years of higher education teaching experience in both public and private universities in the US, the most recent of which was lecturer of rhetoric and writing at Elon University in North Carolina (2009-2015). Currently (2015-present), she is a writing tutor and blogger for the University of Glasgow in Glasgow, Scotland, United Kingdom. Her most recent publications include a book chapter: "Tales of a Freeway Faculty Member" in Adjunct Faculty Voices: Cultivating Professional Development and Community at the Front Lines of Higher Education, Duke University Press: December 2017, and a conference paper entitled "Living is a Drag: Using the (Re)construction of Identity to Survive" at the conference Stories of Illness / Disability in Literature and Comics: Intersections of the Medical, the Personal, and the Cultural, hosted by the Friedrich Schlegel Graduate School of Literary Studies in Berlin, Germany. She also conducts writing workshops for a variety of groups and organizations, the latest of which include being the Keynote Speaker and Workshop Leader of AMG for the Hebridean Men's Group (Cancer Survivors of the Highlands) "Authentic and Therapeutic Writing", Stornoway, Scotland, UK. Her current research and writing focuses on autoethnographic, sociological, and reflexive connections of inherited narratives to the development of identity and voice.

Professor Victoria Shropshire is a member of the NCTE: National Council for Teacher Education (USA) as well as the Postgraduate Gender Network of Scotland and Scotswrite (UK Society of Authors). She is the recipient of the
Jessica Yorke Scholarship English Literature/Creative Writing, awarded for demonstrating talent in, and commitment to, the field of writing for engaging diverse audiences (UK, 2017); Foundation Scotland's Fran Trust (2017); the College of Arts Graduate School Research Support Award (University of Glasgow, UK 2016); and the Writing Excellence Initiative Grant U.S. Library of Congress: Archival Reading Room (Washington, D.C USA 2014).

Sarah Tytler earned a bachelor of arts in international politics from Virginia Wesleyan College (now Virginia Wesleyan University) in Norfolk, VA, USA in 2009 and is currently pursuing her doctorate of fine arts in creative writing from the University of Glasgow, Glasgow, Scotland, UK.

She served for two years in the United States Peace Corps in the Kingdom of Tonga (2009-2011) as a teacher trainer before teaching for the Whitney Point Central School District in Whitney Point, NY. She currently conducts college-level teaching and learning workshops in Glasgow, Scotland, United Kingdom. Her most recent publications include: "'TwitFic', Twine, and Student-Centred Learning: Combining Creativity and Coding in the Classroom", Africa International Journal of Management, Education, and Governance, Volume 2, Issue 3, and "After the Empress Burned Our Cities" in Issue 4 of Spirit's Tincture magazine. Her current research and writing focus on world-building in young-adult (YA) fantasy literature, specifically the socio-political implications of who and what gets left out of authors' secondary worlds; previous research interests include: rural water development in Ghana; autobiographical poetry; and political economic analyses of government environmental policy in Vietnam.

Ms. Tytler is a member of the Society of Children's Book Writers and Illustrators (SCBWI) and the National Peace Corps Association (NPCA). She was a Batten Scholar (US, 2005-2009) and an ASIANetwork Fellow (US, 2007). Most recently, she received a grant from The Fran Trust of Foundation Scotland to travel to Kisii University, Kenya to present original research at the 2017 Eldoret International Conference on Poverty and Sustainable Development in Africa (EIPCPSDA) (UK, 2017). 